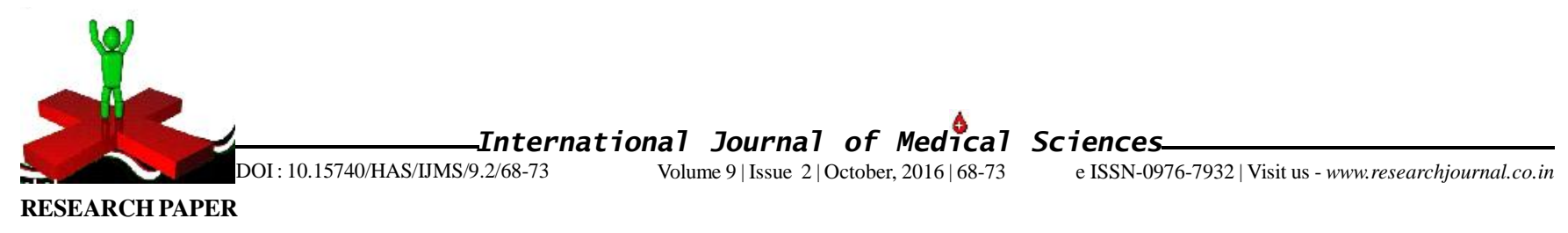

\title{
A Study on Mental Health Profile and Emotional Maturity in Relation to Nutritional Status of Post-Graduate Students
}

\author{
SAGARIKA SABAT, VIJAYETA PRIYADARSHINI AND LIPSA DASH
}

See end of the paper for authors' affiliation

Correspondence to :

VIJAYETA PRIYADARSHINI

Department of Home Science, Govt. Women's College, KEONJHAR (ODISHA) INDIA Email : vijayeta.priyadarshini @ gmail.com

\begin{abstract}
There are concerns about the rates of depression, stress and other psychiatric symptoms among university students along with the unhealthy pattens of food consumption resulting either malnutrition or obesity. This study was aimed to determine the nutritional status, mental health and emotional maturity among 120 post graduate students of Sambalpur University, Odisha. The mean weight, height and BMI were found to be $51.96 \mathrm{~kg}( \pm 7.9893), 1.5671 \mathrm{mts}( \pm 0.0617)$ and $21.142( \pm 3.2536)$, respectively. 25 per cent of the respondents showed poor mental health Significant association was found between BMI and Mental health stats at $\mathrm{p}<0.05$ level.
\end{abstract}

How to cite this paper : Sabat, Sagarika, Priyadarshini, Vijayeta and Dash, Lipsa (2016). A Study on Mental Health Profile and Emotional Maturity in Relation to Nutritional Status of Post-Graduate Students. Internat. J. Med. Sci., 9(2) : 68-73, DOI : 10.15740/HAS/IJMS/9.2/68-73.

\section{KEY WORDS :}

Nutritional status, Mental health, Emotional maturity, Youth 